\title{
Rancangan Atap Otomatis Menggunakan Energi Surya Dengan Sensor LDR Berbasis IoT
}

\author{
Nizam Bayu Mahesa ${ }^{1}$, Novi Dian Nathasia ${ }^{2}$, Ucuk Darusalam ${ }^{3}$ \\ ${ }^{1,2,3}$ Informatika, Fakultas Teknologi Komunikasi dan Informatika, Universitas Nasional \\ e-mail: ${ }^{1}$ nizammbm24@gmail.com, ${ }^{2}$ novidian@civitas.unas.ac.id, ${ }^{3}$ ucuk.darusalam@gmail.com
}

\begin{abstract}
Abstrak
Cuaca yang ada di Indonesia sangat sering mengalami perubahan yang tidak tentu. Sehingga, sulit untuk memprediksi cuaca hujan dan cerah di Indonesia. Cuaca sangat berperan penting pada industri ikan asin, salah satunya dalam hal pengeringan ikan. Pokok permasalahan yang ada apabila turun hujan secara tiba-tiba, dimana pekerja harus mengangkut ikan supaya tidak terkena air hujan. Proses ini sangat kurang efektif dari segi waktu ataupun tenaga. Pada penelitian kali ini akan dirancang sistem untuk membuat alat pengendali atap secara otomatis. Alat tersebut menggunakan mikrokontroler ditambah dengan sensor LDR, yang dimana ketika sensor tidak menerima cahaya matahari maka sensor LDR menerjemahkan bahwa akan hujan, dan kemudian atap akan tertutup secara otomatis. Ketika sensor menerima cahaya matahari maka sensor LDR akan menerjemahkan bahwa keadaan sekitar sedang panas, kemudian atap akan terbuka secara otomatis. Sensor LDR akan mengirimkan data ke ESP8266 yang kemudian data akan dikirimkan ke ThingSpeak berupa data intensitas cahaya dan ESP8266 akan memerintah motor servo untuk menggerakkan atap. Dalam penelitian ini, apabila intesitas cahaya yang masuk kedalam sensor lebih dari 500, maka motor servo akan bergerak kemudian atap akan terbuka dan jikalau intensitas cahaya yang masuk kurang dari 450, maka motor servo akan bergerak untuk menutup atap. Penulis menggunakan mikrokontroler sebagai pengendali atap otomatis. Untuk membuat rancangan alat tersebut penulis membuat prototype atap otomatis menggunakan sensor LDR berbasis mikrokontroler ditambah dengan motor servo.
\end{abstract}

Kata kunci-Atap Otomatis, ESP8266, Sensor LDR

\begin{abstract}
Weather in Indonesia very often experiences erratic changes because Indonesia has two seasons. Thus, it is difficult to predict rainy and sunny weather in Indonesia. Weather plays an important role in the salted fish industry, one of which is the drying of fish. The main problem is when it rains suddenly, where workers have to transport fish so that they are not exposed to rain water. This process is very ineffective in terms of time or effort. In this research, a system will be designed to make a roof controller automatically. This tool uses a microcontroller coupled with an LDR sensor, which when the sensor does not receive sunlight, the LDR sensor will interpret that it will rain, and then the roof will be closed automatically. When the sensor receives sunlight, the sensor LDR will interpret that the environment is hot, then the roof will open automatically. The LDR sensor will send data to the ESP8266 which then the data will be sent to ThingSpeak in the form of light intensity data and the ESP8266 will command the servo motor to move the roof. In this study, if the light intensity entering the sensor is more than 500, the servo motor will move then the roof will open and if the incoming light intensity is less than 450, the servo motor will move to close the roof. The author uses a microcontroller as an automatic roof controller. To make design this tool the authors made an
\end{abstract}


automatic roof prototype using a microcontroller-based LDR sensor coupled with a servo motor.

Keywords-Automatic Roof, ESP8266, Sensor LDR

\section{PENDAHULUAN}

$P^{\prime}$ erubahan cuaca yang sering terjadi di Indonesia ini menyebabkan keresahan bagi sebagian pekerja yang sedang menjemur ikan asin. Pokok permasalahan yang ada apabila turun hujan secara tiba-tiba, dimana pekerja harus mengangkut ikan agar tidak terkena hujan. Proses ini sangat kurang efektif baik dari segi waktu maupun tenaga. Melihat kondisi yang seperti ini, penulis mencoba untuk membantu meringankan beban pekerja dalam proses pengeringan ikan apabila terjadi hujan secara tiba-tiba. Untuk itu dibutuhkan atap otomatis.

Berdasarkan penelitian yang telah dilakukan oleh Yayan Hendrian dan teman-teman dengan memanfaatkan LDR sebagai sensor cahaya dan Arduino Uno sebagai mikrokontroler untuk menggerakan motor DC sesuai dengan input yang ada untuk mengatur jemuran otomatis [1]. Kemudian pada penelitian lainnya yang dilakukan oleh Irwanto dan teman-teman yaitu memanfaatkan sensor air sebagai input untuk mikrokontroler menggerakan atap otomatis menggunakan motor servo. Apabila sensor air tersebut terkena tetesan air hujan, maka akan memberikan input kepada mikrokontroler dan motor servo bergerak berdasarkan perintah mikronkontroler [2]. Kemudian pada penelitian lainnya yang dilakukan oleh Geethika Kilari dan teman-teman yaitu menerapkan Modul Driver LDR dan mikroprosesor untuk mengukur serta mengontrol intensitas cahaya sesuai kebutuhan dari pengguna [3]. Pada penilitian yang dilakukan oleh Elly Mufida dan teman-temannya merancang pengendali atap pada jemuran menggunakan Arduino sebagai mikrokontroler, sensor cahaya dan juga motor DC sebagai alat penggerak atap [4].

Berdasarkan penelitian yang telah ada terkait ini akan menggunakan mikrokontroler yang berfungsi sebagai pengendali atap otomatis dan ditambah juga dengan sensor LDR. Maka penelitian ini akan menggunakan ESP8266 yang terhubung dengan Wi-Fi agar dapat mengirimkan sebuah data ke ThingSpeak dan sebagai mikrokontroler yang dapat mengatur input dari sensor cahaya dan motor servo untuk mengatur atap.

\section{METODE PENELITIAN}

Metode dalam penelitian ini menggunakan metode rancang bangun. Proses perancangan dimulai dari studi literatur seperti menganalisis kebutuhan sistem, analisis hasil simulasi dan lainnya [5]. Seperti pada gambar 1 berikut: 


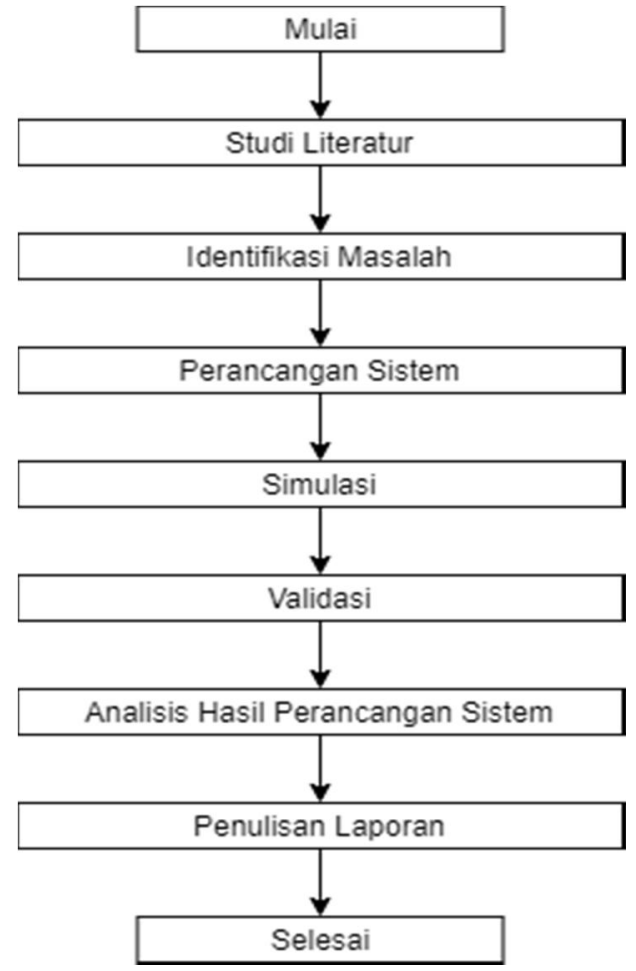

Gambar 1. Alur Penelitian

\subsection{Analisis Kebutuhan Sistem}

Dilakukan analisis yang dibutuhkan sistem ini untuk memilah perangkat apa saja yang dibutuhkan dalam pembangunan sistem [6]. Ada beberapa kebutuhan sistem yang dibutuhkan dalam penelitian ini, sebagai berikut:

\section{1.1Perangkat Lunak}

Yang dibutuhkan dalam perancangan sistem atap otomatis sebagai berikut :
a. Arduino IDE
b. Browser (Chrome, Mozilla, dll)
c. Sistem Operasi (Windows 10)

\section{1.2Perangkat Keras}

Yang dibutuhkan pada sistem atap otomatis ini sebagai berikut :
a. ESP8266
b. Jumper
c. Motor Servo
d. Power Supply
e. Sensor Cahaya atau LDR

\subsection{Rancangan Perangkat}

Pusat untuk mengontrol alat ini yaitu mikrokontroler ESP8266 yang terhubung dengan WiFi untuk menghubungkan ke Cloud Platform (ThingSpeak) dan menggunakan sensor Light Dependent Resistor sebagai pengukur cahaya dan menggunakan Motor Servo sebaagai penggerak atap otomatisnya. Untuk konfigurasi sistemnya dapat dilihat pada gambar 2 dan untuk source code yang dapat menghubungkan ESP8266 ke ThingSpeak dapat dilihat pada gambar 3. 


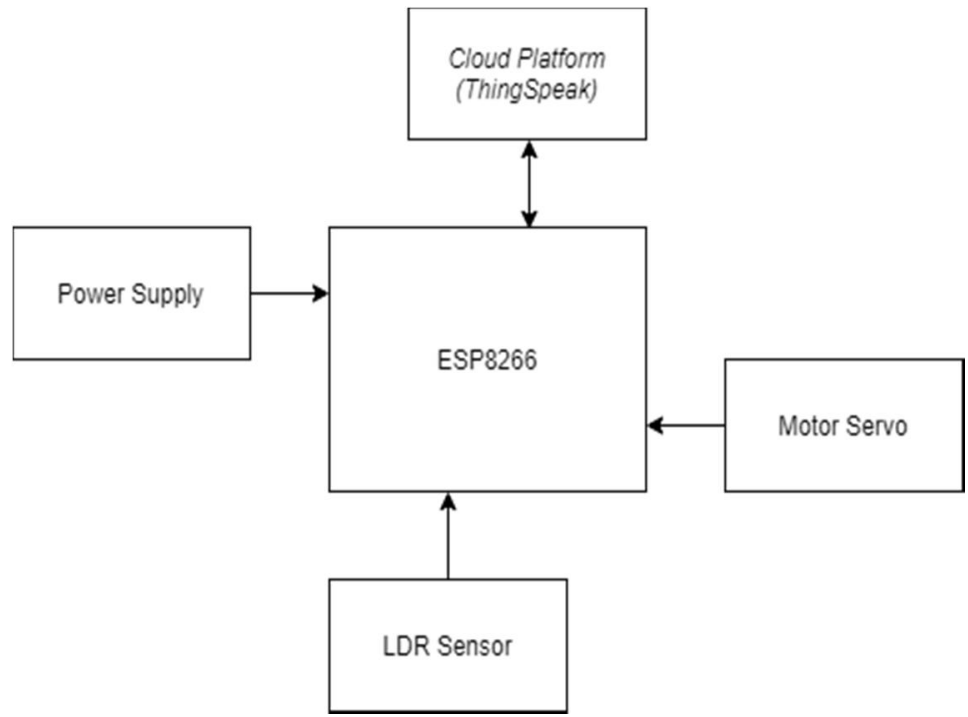

Gambar 2. Diagram Sistem Atap Otomatis

Supaya dapat menghubungkan data intensitas cahaya yang didapat dari sensor LDR ke Cloud Platform ThingSpeak dilakukan menggunakan Software Arduino IDE yang menggunakan bahasa pemrograman $\mathrm{C}$ dan $\mathrm{C}++$, dalam software Arduino IDE harus menambahkan library dan inisial Wi-Fi yang digunakan untuk menghubungkan ESP8266 dengan internet. Kemudian masukkan IP Address web ThingSpeak beserta API Keys channels.

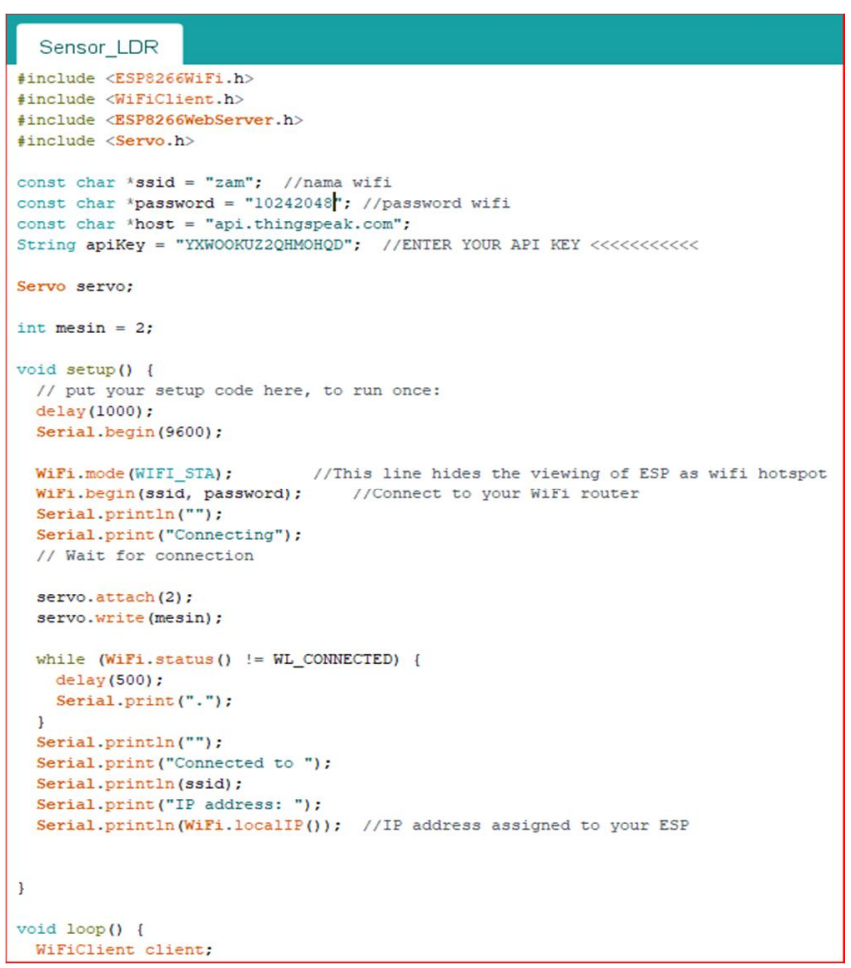

Gambar 3. Source Code Konfigurasi Penghubung Data ke ThingSpeak Dengan Arduino IDE 
Untuk flowchart rancangan atap otomatis dapat dilihat pada gambar 4 yang merupakan flowchart rancangan perangkat yang diawali dengan mulai menginisialisasi kemudian mengimpor nilai sensor LDR ke dalam thingspeak. Membuat nilai variable LDR untuk kapasitas dari intensitas cahaya yang diberikan untuk sensor LDR. Dalam kondisi awal apabila nilai LDR $\geq 500$ maka atap akan terbuka, sedangkan apabila nilai LDR $\leq 500$ maka atap akan tertutup.

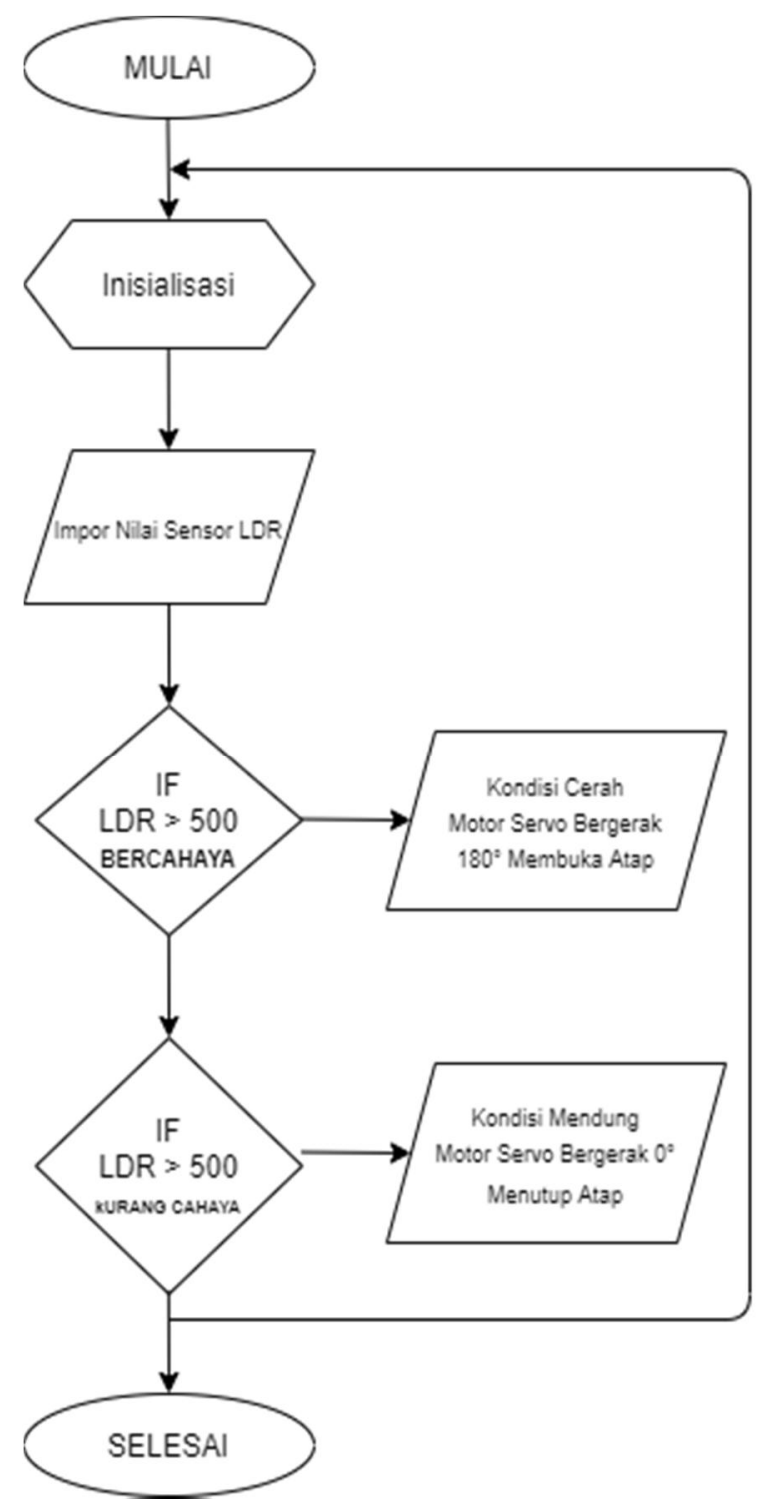

Gambar 4. Flowchart Sistem Atap Otomatis

\subsection{Sensor Cahaya atau LDR}

LDR merupakan sebuah alat yang berfungsi mengubah foton menjadi elektron, yang umumnya satu foton hanya bisa membangkitkan satu elektron [7]. 


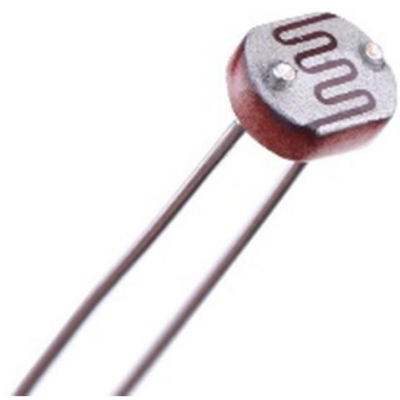

Gambar 5. Sensor Cahaya atau LDR

\subsection{ESP8266}

ESP8266 merupakan sistem pada chip dan jaringan Wi-Fi yang memiliki aplikasi perangkat lunak. Perangkat ini terintegrasi dengan sensor port GPIO (General Purpose Input Output), aplikasi mesin khusus lainnya dan juga membutuhkan sedikit sirkuit eksternal karena chip yang sangat terintegrasi [8].

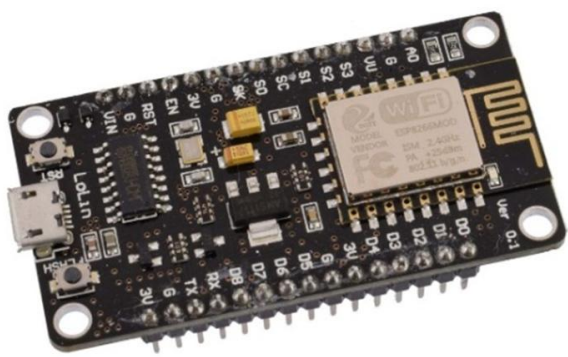

\subsection{Motor Servo}

Gambar 6. ESP8266

Motor servo memiliki tiga kabel, yang digunakan sebagai catu daya, ground dan kontrol. Untuk menentukan motor ketika memutar baling-baling ke posisi tertentu merupakan fungsi dari kabel kontrol [9].

\subsection{Arduino IDE}

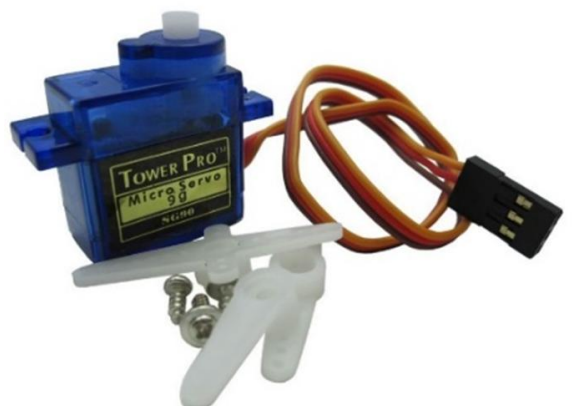

Gambar 7. Motor Servo

Arduino IDE merupakan sebuah platform yang menggunakan Bahasa pemrograman C dan $\mathrm{C}++$, penelitian ini digunakan untuk memprogram mikrokontroler yang didalamnya terdapat berbagai macam library pada penggunaan mikrokontroler salah satunya ESP8266. 


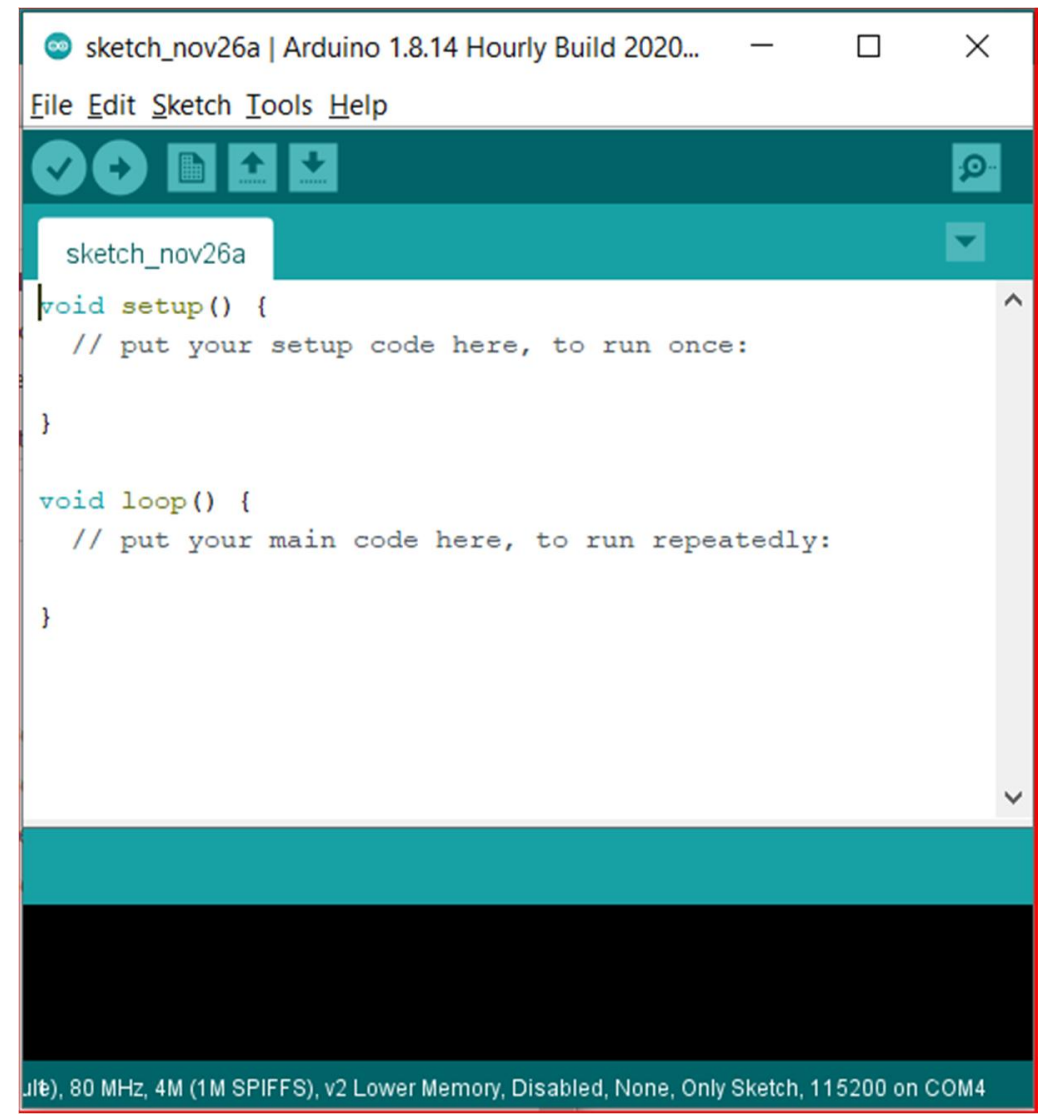

Gambar 8. Software Arduino IDE

\section{HASIL DAN PEMBAHASAN}

Pembahasan dari hasil yang dilakukan bertujuan untuk mengukur data intensitas cahaya matahari yang selanjutnya data yang didapat akan dijadikan sebagai acuan untuk menentukan batasan pada program atap otomatis, berikut hasil dan pembahasan:

\subsection{Pengumpulan Data}

Berdasarkan hasil dan pembahsan didapat data yang dihasilkan dari sensor LDR, yang dimana dilakukan pengumpulan data pada satu hari (pagi, siang, sore). Selanjutnya data yang diperoleh akan digunakan sebagai acuan untuk menentukan batasan pada program atap otomatis. Dari hasil pengumpulan data yang dilakukan tersaji pada tabel berikut.

Tabel 1. Hasil Pengujian Sensor LDR

\begin{tabular}{|c|c|c|}
\hline \multirow{2}{*}{ Sensor } & Waktu & Rata-rata Data yang Diukur \\
\hline \multirow{3}{*}{ LDR } & Pagi & 598.5 \\
\cline { 2 - 3 } & Siang & 686.3 \\
\cline { 2 - 3 } & Sore & 388.2 \\
\hline
\end{tabular}

Berikut data yang ditampilkan dalam ThingSpeak pada gambar 9 adalah sebuah uji coba terhadap cahaya matahari di pagi hari mendapatkan nilai rata-rata data intensitas cahaya bernilai 
Jatisi

ISSN 2407-4322

Vol. 8, No. 1, Maret 2021, Hal. 250-260

E-ISSN 2503-2933 257

598.5 yang dimana atap akan terbuka, berdasarkan rancangan yang sudah dibuat apabila nilai dari intensitas cahaya adalah $\leq 450$ maka atap akan tertutup.

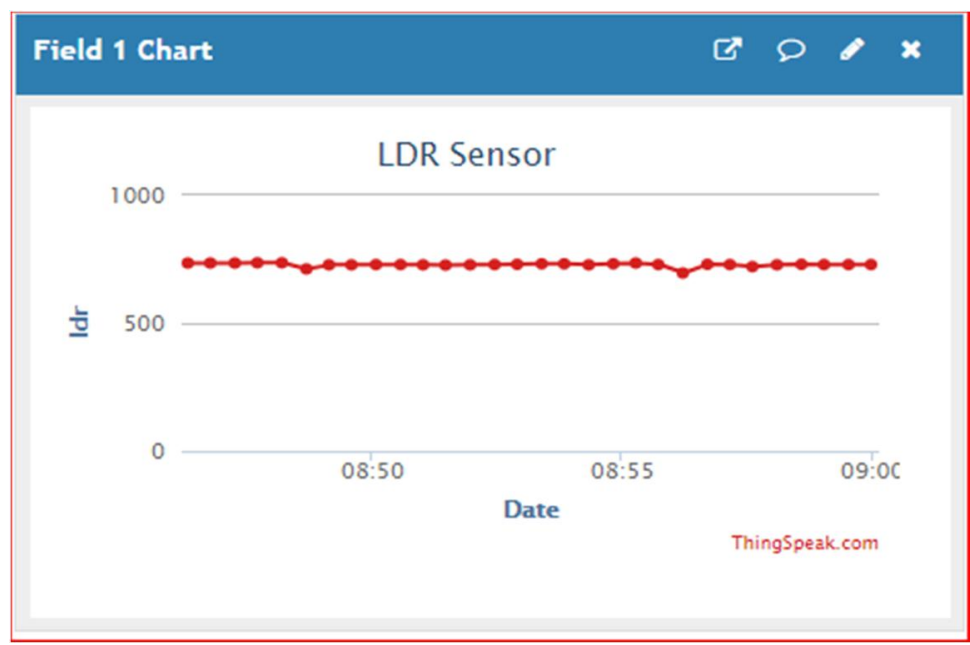

Gambar 9. Grafik Hasil Pengukuran Intensitas Cahaya Pagi Hari

Pada gambar 10 merupakan pengujian kedua di siang harinya yang mendapatkan nilai rata-rata data intensitas cahaya hingga bernilai 686.3 yang dimana atap tetap terbuka dikarenakan data intensitas yang di dapat masih $\geq 500$.

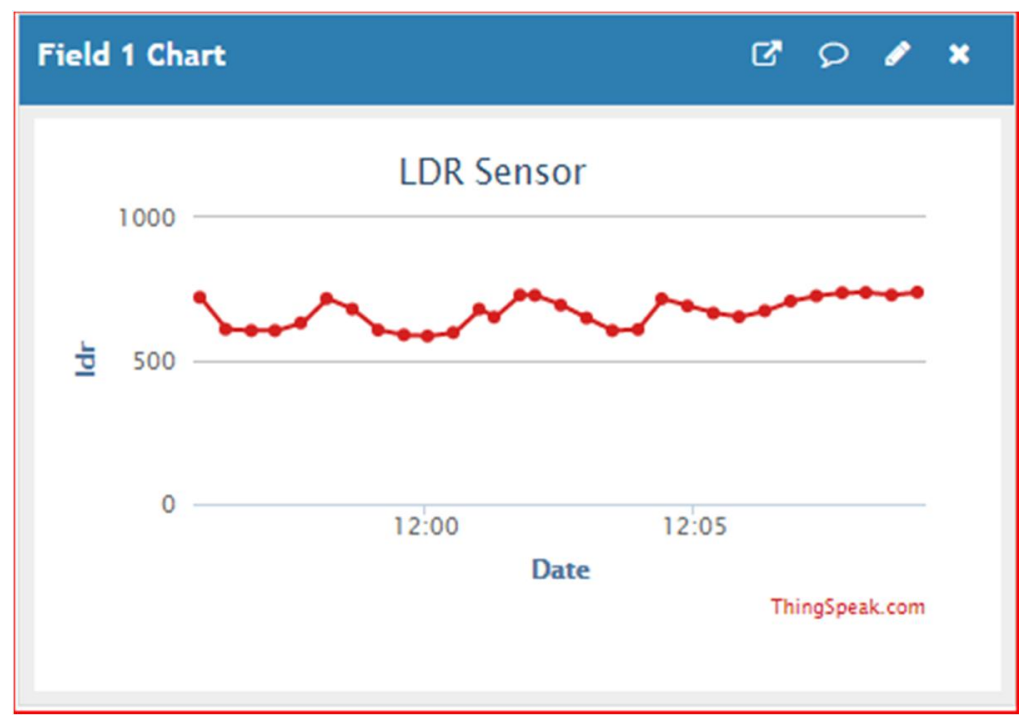

Gambar 10. Grafik Hasil Pengukuran Intensitas Cahaya Siang Hari

Pengujian terakhir dilakukan pada sore hari yang dapat dilihat pada gambar 11 dengan nilai rata-rata data intensitas cahaya 388.2 yang dimana atap akan tertutup disebabkan intensitas cahaya yang di dapat $\leq 450$. 


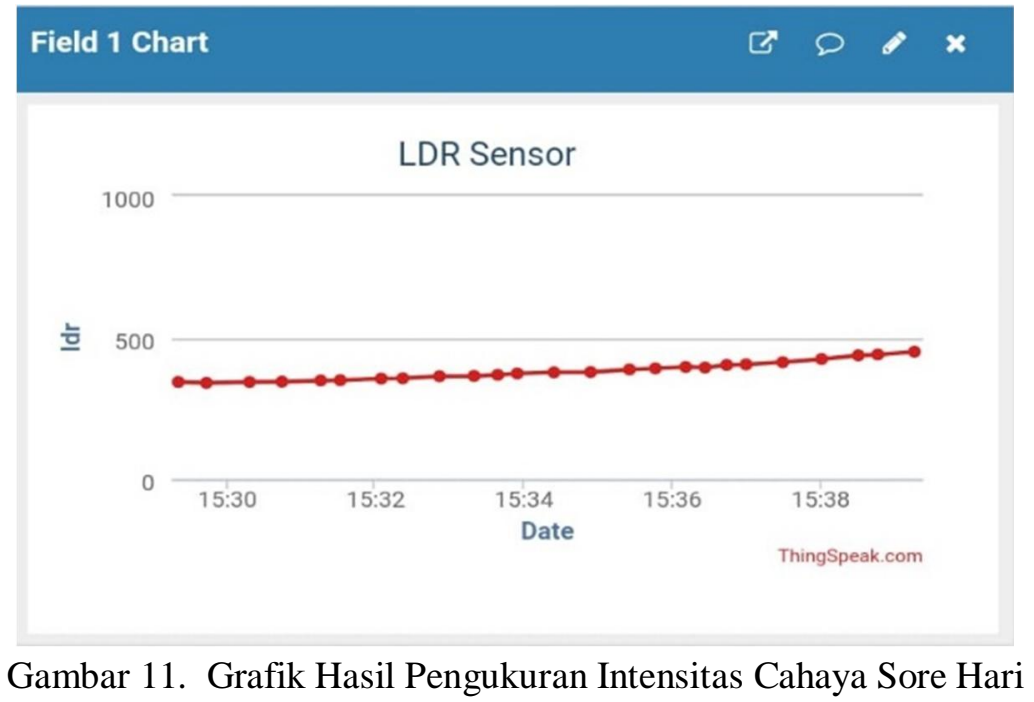

\subsection{Perancangan Sistem}

Dari data yang dikumpulkan selanjutnya dijadikan sebagai acuan untuk menentukan logic pemrograman atap otomatis dengan Arduino IDE dan dapat disimpulkan bahwa untuk dapat membuka atap otomatis dibutuhkan nilai minimum intensitas cahaya pada sensor sebesar $\leq 450$ untuk menggerakkan motor servo dan nilai maksimum intensitas cahaya pada sensor sebesar $\geq 500$ untuk menggerakkan motor servo [10]. Pada gambar 8 adalah sebuah source code cara sensor LDR menerima data yang berfungsi supaya dapat menggerakkan motor servo $0^{\circ}$ $180^{\circ}$.

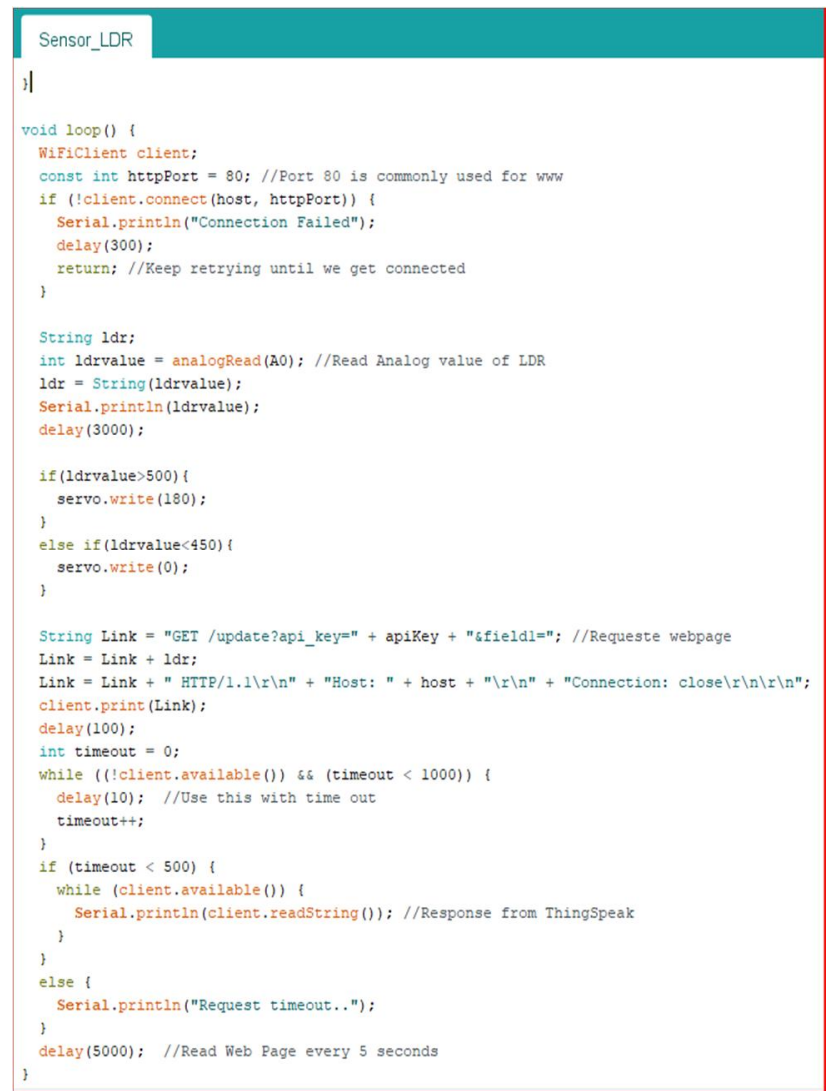

Gambar 12. Source Code untuk Sensor LDR 
Dari data sensor LDR kemudian diproses oleh ESP8266 sesuai dengan logic yang telah ditentukan Berikut merupakan monitoring hasil output dari pengujian sensor LDR yang dapat disimpulkan bahwa atap akan terbuka apabila data yang diukur telah mencapai batasan nilai yang telah ditentukan. Dari hasil pembuatan perancangan sistem atap otomatis selanjutnya dilakukan proses pengujian alat.

Tabel 2. Hasil Pengujian Sistem Atap Otomatis

\begin{tabular}{|c|c|c|}
\hline Sensor LDR & Motor Servo & Status Atap \\
\hline$\geq 500$ & $\begin{array}{c}\text { Servo berputar ke } \\
\text { sudut } 180^{\circ}\end{array}$ & Terbuka \\
\hline$\leq 450$ & $\begin{array}{c}\text { Servo berputar ke } \\
\text { sudut } 0^{\circ}\end{array}$ & Tertutup \\
\hline
\end{tabular}

\section{KESIMPULAN}

Berdasarkan pengujian pada atap otomatis menggunakan sensor LDR diatas, dapat diambil kesimpulan bahwa pemanfaatan teknologi dalam bidang IoT yang menggunakan mikrokontroler ESP8266 dan sensor LDR dapat bekerja dengan baik sesuai perancangan yang telah dibuat.

Alat ini akan berfungsi apabila data intensitas cahaya yang masuk adalah $\geq 500$ maka atap akan terbuka dan akan tertutup apabila data intensitas cahaya yang masuk adalah $\leq 450$.

\section{SARAN}

Saran untuk penelitian selanjutnya sebaiknya pada Atap Otomatis menggunakan tambahan sensor air yang dapat dikendalikan dan dipantau dari jarak jauh menggunakan sistem berbasis Android dan untuk proses pengiriman data lebih diperhatikan lagi supaya pada pengiriman data dapat memangkas waktu sehingga tidak delay.

\section{DAFTAR PUSTAKA}

[1] Y. Hendrian, Y. Pribadi Yudatama, and V. Surya Pratama, Jemuran Otomatis Menggunakan Sensor LDR, Sensor Hujan dan Sensor Kelembaban Berbasis Arduino Uno, Vol. VI, No. 1, pp. 135-138, 2020, doi: 10.31294/jtk.v4i2.

[2] Irwanto, E. Permata, and D. Aribowo, Rancangan Prototype Alat Jemuran Otomatis Menggunakan Sensor Air dan Sensor Cahaya Berbasis Mikrokontroler Arduino, pp. 133-139, 2019.

[3] G. Kilari, R. Mohammed, and R. Jayaraman, Automatic Light Intensity Control using Arduino UNO and LDR, pp. 0862-0866, 2020, doi: 10.1109/iccsp48568.2020.9182238.

[4] E. Mufida, S. Nurajizah, and A. Abas, Pengendali Atap Jemuran Otomatis Dengan Sensor Cahaya Berbasiskan Mikrokontroler ATmegal6, Konf. Nas. Ilmu Sos. Teknol., pp. 269-274, 2013. 
[5] P. Maulana, U. Darusalam, and N. D. Nathasia, Road Guides and Special Location Monitoring for Blind People Using Ultrasonic Sensors and Microcontroller Based GPS Modules, J. Mantik, Vol. 3, No. 4, pp. 444-450, 2020, [Online]. Available: https://iocscience.org/ejournal/index.php/mantik/index.

[6] N. Nasrudin, N. M. Ilis, T. P. Juin, T. T. K. Chun, L. W. Zhe, and F. Z. Rokhani, Analysis of The Light Dependent Resistor Configuration for Line Tracking Robot Application, Proc. - 2011 IEEE 7th Int. Colloq. Signal Process. Its Appl. CSPA 2011, pp. 500-502, 2011, doi: 10.1109/CSPA.2011.5759930.

[7] P. V. Vimal and K. S. Shivaprakasha, IOT Based Greenhouse Environment Monitoring and Controlling System using Arduino Platform, 2017 Int. Conf. Intell. Comput. Instrum. Control Technol. ICICICT 2017, Vol. 2018-Janua, pp. 1514-1519, 2018, doi: 10.1109/ICICICT1.2017.8342795.

[8] P. Srivastava, M. Bajaj, and A. S. Rana, Overview of ESP8266 Wi-Fi module based Smart Irrigation System using IOT, 2018 Fourth Int. Conf. Adv. Electr. Electron. Information, Commun. Bio-Informatics, pp. 1-5, 2018.

[9] S. V Devika, S. Khamuruddeen, S. Khamurunnisa, J. Thota, and K. Shaik, Arduino Based Automatic Plant Watering System, Int. J. Adv. Res. Comput. Sci. Softw. Eng., Vol. 4, No. 10, pp. 449-456, 2014.

[10] Deny Siswanto \& Slamet Winardi, Jemuran Pakaian Otomatis Menggunakan Sensor Hujan, Narodroid, Vol. 1, No. 2, pp. 66-73, 2015. 